\title{
Kursbuch 171
}

\section{Besser optimieren}

Jens Bisky Brief eines Lesers - Birger P. Priddat Kapitalismus als Religion - Niels Pfläging Kaputtoptimieren - Jörn Müller-Quade Geheimnis Kryptografie - Lydia Rea Hartl Menschenoptimierung im Netzzeitalter - Peter Felixberger Das Coca-Cola-Komplott - Thorsten Baensch The Coca Cola Collection - James Shikwati Die Optimierungsfalle - Ingo Rechenberg Optimierbarkeit optimieren - Sabine Maasen Gut ist nicht gut genug • Irmhild Saake Sterben vor Publikum - Christian Gansch, Armin Nassehi Der perfekte Klang Gert Heidenreich Der Beste 